\title{
Frequency of infections and risk of asthma, atopy and airway hyperresponsiveness in children
}

\author{
E. von Mutius*, S. Illi*, T. Hirsch", W. Leupold", U. Keil ${ }^{+}$, S.K. Weiland ${ }^{+}$
}

Frequency of infections and risk of asthma, atopy and airway hyperresponsiveness in children. E. von Mutius, S. Illi, T. Hirsch, W. Leupold, U. Keil, S.K. Weiland. (C)ERS Journals Ltd 1999.

ABSTRACT: The role of repeated infections early in life in the development of childhood asthma and allergies has not been clarified. The aim of this study was to investigate the effect of repeated episodes of fever and antibiotic treatments during the first years of life on the prevalence of asthma, bronchial hyperresponsiveness (BHR), and atopy at school age in a representative population.

Random samples of schoolchildren aged 5-7 yrs $(n=7,545)$ and 9-11 yrs $(n=7,498)$ were studied using the International Study of Asthma and Allergies in Childhood (ISAAC) phase II protocol. To assess the prevalence of disease and early childhood exposures, parental questionnaires were administered (response rates $82.2 \%$ and $\mathbf{8 5 . 3 \%}$, respectively). In addition, children underwent skin prick tests, hypertonic saline challenge and blood sampling for the measurement of serum immunoglobulin (Ig)E.

Repeated episodes of fever and antibiotic treatment in early life were strongly associated with the prevalence of asthma (odds ratio $(O R)=7.95 ; 95 \%$ confidence interval (CI) 6.02-10.50) and current wheeze at school age. Within asthmatic children the number of fever episodes and antibiotic courses were strongly inversely related to the prevalence of atopy $(\mathrm{OR}=0.25 ; 95 \% \mathrm{CI} 0.11-0.54$ for skin test reactivity) and $\mathrm{BHR}$ $(\mathrm{OR}=0.31 ; 95 \% \mathrm{CI} 0.10-0.92)$. Furthermore, asthmatic children with recurrent early childhood infections were at a lower risk of being symptomatic at school age. When considering atopic and nonatopic asthmatic children separately, the highest risk of asthma with repeated early childhood infections was found for nonatopic asthma $(\mathrm{OR}=24.29 ; 95 \%$ CI $11.86-49.76)$.

These findings suggest that a subgroup of children with a triggering or inducing of asthmatic symptoms through repeated early childhood infections exists within the "asthma syndrome" which has a better prognosis and is less related to the atopic phenotype.

Eur Respir J 1999; 14: 4-11.
*University Children's Hospital, Klinikum Innenstadt, Munich, Germany. "University Children's Hospital Dresden, Germany. Institute of Epidemiology and Social Medicine, University of Münster, Germany.

Correspondence: E. von Mutius

Klinikum Innenstadt

Lindwurmstr. 4

D-80337 München

Germany

Fax: 498951604452

Keywords: Asthma

atopy

children

epidemiology

infections

Received: October 191998

Accepted after revision March 51999

This work was supported by the Bundesministerium für Bildung, Forschung und Technologie (German Ministry for the Sciences and Technology).
There is an ongoing debate about the potential harmful or protective effect of early childhood infections on the development of childhood asthma and atopic diseases. Follow-up studies of children with proven respiratory syncytial virus (RSV) bronchiolitis have shown a slightly increased prevalence of repeated mild episodes of wheeze during the first 4 yrs of life, reductions in pulmonary function and increased prevalence of airway hyperresponsiveness [1-3]. Some authors also reported a positive association between infant bronchiolitis and atopic sensitization at school age [4], but others failed to confirm this finding $[2,3]$.

In contrast, the results of recent studies suggest that repeated bacterial and viral infections early in childhood may exert a protective effect on the development of atopic diseases. In the Fiji Islands, FLYNN [5, 6] showed that in the indigenous children with frequent respiratory infections and a high hospital admission rate for pneumonia, the prevalence of asthma and airway hyperresponsiveness was lower than in the less exposed children. A recent

For editorial comments see page 2 report from southern Italy [7] showed that military students who were seropositive for hepatitis A also had a significantly lower prevalence of asthma and atopy than subjects without antibodies to hepatitis A. Finally, in the prospective Tucson Cohort Study [8], children who had nonwheezing lower respiratory tract illnesses, such as pneumonia and tracheobronchitis, during the first $3 \mathrm{yrs}$ of life had subsequently reduced skin test reactivity and depressed levels of total serum immunoglobulin $(\mathrm{Ig}) \mathrm{E}$ at the age of 6 yrs. In turn, very little is known about the potential effects of antibiotic treatment on the development of childhood asthma and atopic diseases.

The aim of this analysis was to relate the number of early childhood episodes of fever and antibiotic treatment to the prevalence of asthma, atopy, baseline pulmonary function and airway hyperresponsiveness at school age in a large representative population. Random samples of schoolchildren aged 5-7 yrs, and 9-11 yrs from two German cities were studied using the International Study of Asthma and Allergies in Children (ISAAC) phase II modules which have been recently published in detail [9]. 


\section{Methods}

\section{Study population and study design}

ISAAC phase II cross-sectional surveys were performed in Dresden, a city in Saxony in the south-eastern part of Germany with $\sim 480,000$ inhabitants, and in Munich, in the south-western part of the country with $\sim 1.3$ million inhabitants. In each city, random samples of school classes were selected in two age groups: school beginners aged 5-7 yrs and schoolchildren of the fourth grade aged 9-11 yrs. Between August 1995 and December 1996, comprehensive questionnaires were given to parents for self-completion and children underwent skin prick tests, blood sampling, lung function testing and bronchial challenge if written informed consent had been obtained from the parents.

\section{Questionnaires}

The questionnaires included the ISAAC core questions on symptoms of asthma, allergic rhinitis and atopic ecze$\mathrm{ma}$, which have been reported in detail elsewhere $[10,11]$. Current wheeze was defined as wheezing in the last 12 months. In addition, parents were asked "Did a doctor ever diagnose any of the following diseases in your child: a) asthma, b) asthmatic, spastic or obstructive bronchitis, c) bronchitis?". Children were defined as having asthma if their parents reported that asthma had been diagnosed at least once or that a doctor had diagnosed asthmatic, spastic or obstructive bronchitis more than once. Parents of asthmatic children were also asked how often respiratory symptoms had occurred in the previous 12 months. The prevalence of hay fever and atopic eczema was assessed by affirmative responses to the questions "Has a doctor ever diagnosed hay fever in your child?", and "Has a doctor ever diagnosed atopic dermatitis in your child?".

The frequency of infections during the first years of life was retrospectively assessed by asking the parents "How many fever episodes $\left(>38.5^{\circ} \mathrm{C}\right)$ did your child have in the first year of life?", and "How many antibiotic courses (for $>3$ consecutive days) did your child have in the first three years of life?" In addition, the questionnaire included detailed questions about the child's nationality, the family history of atopic diseases, the number of siblings, and several other potential confounding factors such as environmental tobacco smoke exposure and parental education.

The reliability of responses to the questionnaire was assessed by administering the questionnaire a second time to a total of 347 subjects within a 12-month period. For a doctor's diagnosis of asthma, the kappa was $0.81(0.70$ $0.93)$, for wheeze in the past 12 months $0.70(0.48-0.92)$, for the number of fever episodes $0.57(0.51-0.65)$ and for the number of antibiotic treatments $0.63(0.57-0.69)$. The repeatability of questions relating to the number of fever episodes and antibiotic courses did not differ between asthmatic and nonasthmatic children (data not shown).

\section{Skin prick tests}

All children of the fourth grade were invited to participate in skin prick testing, whereas for the younger age group only a random subsample $(n=2,328$ in Dresden and $n=1,875$ in Munich) was selected. The sensitivity to six common aeroallergens (Dermatophagoides pteronyssinus, D. farinae, tree pollen, mixed grass pollen, Alternaria tenuis and cat dander) was assessed using highly standardized extracts (ALK, Hörsholm, Denmark) and ALK lancets. A positive (histamine $10 \mathrm{mg} \cdot \mathrm{mL}^{-1}$ ) and negative (diluent) control were added. Fifteen minutes after the application of the allergen extracts on the volar side of the left forearm, the weal reaction was measured in $\mathrm{mm}$. The weal size was defined as the mean of the longest diameter and the length of its perpendicular diameter. Children with a weal reaction $\geq 3 \mathrm{~mm}$ after subtraction of the reaction to the negative control, to one or more of the six allergens tested, were considered to be atopic.

\section{Blood sampling and laboratory analyses}

As with skin prick testing, all children of the fourth grade were asked to provide a blood sample, whereas for the younger age group only a random subsample $(n=2,328$ in Dresden and $n=1,875$ in Munich) was selected. Serum was separated by centrifugation, frozen and stored at $-70^{\circ} \mathrm{C}$ before analysis. A screening test (Sx1 test; Pharmacia, Uppsala, Sweden) was used to detect specific serum IgE antibodies to a wide array of aeroallergens $(D$. pteronyssin$u s$, mixed grass pollen, birch pollen, mugwort pollen, cat dander, dog dander and Cladosporium herbarum) in one central laboratory at the University of Berlin (H. Renz). Atopic sensitization was assumed to be present if a level $\geq 0.7 \mathrm{kU} \cdot \mathrm{L}^{-1}$ of specific serum IgE was measured. In addition, levels of total serum IgE were measured in a 50\% random subsample of all children providing blood samples using the Insulite system (DPC Biermann, Bad Nauheim, Germany).

\section{Pulmonary function testing and bronchial challenge}

Because of the long duration of the bronchial challenge protocol, only a random subsample of the 9-11-yr-old children was invited to participate $(n=1,999$ in Dresden and $\mathrm{n}=2,019$ in Munich). Lung function was measured with a spirometer (MasterScope; Jäger, Würzburg, Germany). The criteria for completion of reproducible and satisfactory spirograms as set by the American Thoracic Society [12] were followed. The highest of two reproducible forced expiratory volume in one second (FEV1) readings was recorded as the baseline FEV1.

Airway responsiveness was assessed using a 4.5\% hyperosmolar saline challenge $[9,13]$ which was delivered by ultrasound nebulizers (DeVilbiss; Sunrise Medical, Langen, Germany). Each subject whose baseline FEV1 was $>75 \%$ of predicted [14] inhaled the saline solution for periods of increasing duration $(0.5,1,2,4$ and $8 \mathrm{~min})$. The challenge was stopped after the FEV 1 had fallen by at least $15 \%$ or if the total inhalation period of $15.5 \mathrm{~min}$ had been completed.

All study methods had been approved by the ethics committee of the University of Münster (Co-ordination and Data Centre). 


\section{Statistical analyses}

Chi-squared tests and Mantel-Haentzel statistics for trend were performed for comparisons between groups. To assess the risk of asthma with repeated episodes of fever and antibiotic treatments, prevalence odds ratios (ORs) were calculated. Multivariate logistic regression analysis was used to assess the independent effects of increasing numbers of fever episodes and antibiotic courses on asthma, atopy and airway hyperresponsiveness while adjusting for several potential confounding factors such as family history of atopy, number of siblings, parental education, study area and school grade. Likewise, the effects of increasing exposure to early childhood infections on baseline pulmonary function were estimated by calculating multivariate linear regression models controlling for sex, height, weight, study area, passive smoke exposure, and a family history of atopy. The SAS software package version 6.12 (SAS Institute Inc., Cary, NC, USA) was used for all computations.

\section{Results}

The questionnaire was distributed to 7,534 children in Dresden and to 7,509 children in Munich (table 1). Parents of 6,357 (84.4\%) children in Dresden and 6,244 (83.2\%) children in Munich returned the questionnaire. The proportion of children not of German nationality was $0.5 \%(n=31)$ in Dresden and 23.1\% $(n=1,431)$ in Munich. To keep the study populations as similar as possible with regard to ethnic background [15], the analysis was restricted to children with German nationality. Of the eligible German children who returned the questionnaire, skin prick tests were obtained from 3,597 (72.4\%) children in Dresden and 2,577 (69.5\%) children in Munich. The response rate for bronchial challenge and blood sampling was lower than the response rate for skin prick testing (table 1). However, a significant participation bias is unlikely to have occurred since the prevalence of atopic diseases in the children and their parents, and the distribution of several confounding factors (parental education, family size, passive smoke exposure, sex, age) was similar for participating and nonparticipating children (data not shown).

The number of fever episodes during the first year of life and the number of antibiotic courses during the first 3 yrs of life were associated with a higher risk of asthma and current wheeze at school age after adjusting for several confounding factors (table 2). For example, children who were treated with antibiotics at least six times during the first 3 yrs of life had an eight-fold higher risk of asthma and a three-fold higher risk of wheezing at school age. This relation was stronger for children of the younger age group than for the fourth grade children (data not shown). No effect modification by sex, family history of atopy or asthma, and the number of siblings was seen (data not shown). A similar though less strong association was found between the frequency of fever episodes and antibiotic courses during the first years of life and a doctor's diagnosis of hay fever and atopic dermatitis (data not shown). This relation may, however, be attributable to the simultaneous occurrence of asthma and hay fever in a subject. Only a weak association between the frequency of fever episodes and antibiotic courses, respectively, and the prevalence of hay fever or atopic dermatitis without symptoms or a diagnosis of asthma was found (table 2). In all these analyses, similar results were obtained in both study areas (data not shown).

In contrast, no significant trend between the number of early childhood fever episodes and antibiotic courses and the manifestation of atopic sensitization as assessed by skin prick tests and radioallergosorbent test (RAST) (Sx1) was found for the whole population (table 3 ). Similar nonsignificant results were obtained when using continuous

Table 1. - Response rates and characteristics of the study subjects

\begin{tabular}{|c|c|c|c|c|c|c|c|c|}
\hline & \multicolumn{4}{|c|}{ Dresden } & \multicolumn{4}{|c|}{ Munich } \\
\hline & \multicolumn{2}{|c|}{ First grade } & \multicolumn{2}{|c|}{ Fourth grade } & \multicolumn{2}{|c|}{ First grade } & \multicolumn{2}{|c|}{ Fourth grade } \\
\hline & $\%$ & $\mathrm{n} /$ No. & $\%$ & n/No. & $\%$ & n/No. & $\%$ & n/No. \\
\hline \multicolumn{9}{|l|}{ Response rates } \\
\hline Questionnaire & 85.7 & $3312 / 3866$ & 83.0 & $3045 / 3668$ & 78.6 & $2890 / 3679$ & 87.6 & $3354 / 3830$ \\
\hline German children & 99.7 & $3300 / 3310$ & 99.3 & $3017 / 3038$ & 75.2 & $2165 / 2879$ & 78.5 & $2612 / 3329$ \\
\hline Skin prick tests & 69.5 & 1355/1951 & 74.3 & $2242 / 3017$ & 69.7 & $765 / 1098$ & 69.4 & $1812 / 2612$ \\
\hline Serum samples & 48.8 & $952 / 1951$ & 68.5 & $2068 / 3017$ & 51.4 & $564 / 1098$ & 51.0 & $1331 / 2612$ \\
\hline Bronchial challenge & - & - & 63.8 & $1042 / 1633$ & - & - & 65.5 & $904 / 1381$ \\
\hline \multicolumn{9}{|l|}{ Characteristics } \\
\hline Age yrs* & 5 & $(4-7)$ & 10 & $(7-13)$ & 6 & $(5-7)$ & 9 & $(7-11)$ \\
\hline Sex $\%$ males & 52.3 & $1724 / 3299$ & 51.9 & $1565 / 3016$ & 50.9 & $1102 / 2165$ & 49.3 & $1288 / 2611$ \\
\hline \multicolumn{9}{|c|}{ Number of fever episodes in 1 st yr of life } \\
\hline Never & $18.7^{\circ}$ & $572 / 3057$ & 18.9 & $536 / 2832$ & 20.2 & $406 / 2007$ & 24.6 & $602 / 2445$ \\
\hline $1-2$ & 55.4 & $1695 / 3057$ & 48.3 & $1368 / 2832$ & 53.5 & $1073 / 2007$ & 48.8 & $1193 / 2445$ \\
\hline $3-4$ & 17.8 & $545 / 3057$ & 19.1 & $542 / 2832$ & 16.8 & $338 / 2007$ & 16.7 & $408 / 2445$ \\
\hline$\geq 5$ & 8.0 & $245 / 3057$ & 13.6 & $386 / 2832$ & 9.5 & $190 / 2007$ & 9.9 & $242 / 2445$ \\
\hline \multicolumn{9}{|c|}{ Number of antibiotic courses in 1st 3 yrs of life } \\
\hline Never & 14.5 & $429 / 2961$ & 14.5 & $406 / 2795$ & 32.9 & $673 / 2045$ & 34.6 & $855 / 2472$ \\
\hline $1-2$ & 34.2 & $1014 / 2961$ & 31.4 & $877 / 2795$ & 40.4 & $827 / 2045$ & 39.5 & $976 / 2472$ \\
\hline $3-5$ & 34.1 & $1010 / 2961$ & 30.8 & $862 / 2795$ & 20.8 & $426 / 2045$ & 18.8 & $465 / 2472$ \\
\hline$\geq 6$ & 17.2 & $508 / 2961$ & 23.3 & $650 / 2795$ & 5.8 & $119 / 2045$ & 7.1 & $176 / 2472$ \\
\hline
\end{tabular}

Data are presented as the percentage of responders (\%) and the number of responders (n) from the total number of subjects invited to participate in the study (No.), except where indicated. *: median (range). 
Table 2. - Number of fever episodes and antibiotic courses during the first year of life and risk* of atopic diseases

\begin{tabular}{|c|c|c|c|c|}
\hline Characteristics & $\begin{array}{l}\text { Asthma } \\
(\mathrm{n}=8765)\end{array}$ & $\begin{array}{l}\text { Current wheeze } \\
\quad(\mathrm{n}=8808)\end{array}$ & $\begin{array}{c}\text { Hay fever } \\
(\mathrm{n}=7456)\end{array}$ & $\begin{array}{l}\text { Eczema }^{+} \\
(\mathrm{n}=7350)\end{array}$ \\
\hline \multicolumn{5}{|c|}{ Number of fever episodes during 1st year } \\
\hline Never & 1.00 & 1.00 & 1.00 & 1.00 \\
\hline \multirow[t]{2}{*}{$1-2$} & 1.13 & 1.06 & 1.07 & 1.15 \\
\hline & $(0.90-1.42)$ & $(0.86-1.32)$ & $(0.82-1.41)$ & $(0.97-1.37)$ \\
\hline $3-4$ & 1.89 & 1.47 & 1.06 & 1.14 \\
\hline \multirow{2}{*}{$\geq 5$} & $\begin{array}{c}(1.47-2.44) \\
352\end{array}$ & $\begin{array}{c}(1.15-1.89) \\
202\end{array}$ & $\begin{array}{c}(0.76-1.49) \\
1.18\end{array}$ & $\begin{array}{c}(0.92-1.42) \\
1.49\end{array}$ \\
\hline & $(2.71-4.58)$ & $(1.54-2.65)$ & $(0.79-1.75)$ & $(1.16-1.92)$ \\
\hline \multicolumn{5}{|c|}{ Number of antibiotic courses during first $3 \mathrm{yrs}$} \\
\hline Never & 1.00 & 1.00 & 1.00 & 1.00 \\
\hline \multirow[t]{2}{*}{$1-2$} & 1.64 & 1.18 & 1.12 & 1.26 \\
\hline & $(1.26-2.13)$ & $(0.93-1.49)$ & $(0.84-1.50)$ & $(1.05-1.52)$ \\
\hline \multirow[t]{2}{*}{$3-5$} & 3.27 & 1.64 & 1.16 & 1.50 \\
\hline & $(2.51-4.26)$ & $(1.29-2.08)$ & $(0.85-1.59)$ & $(1.23-1.82)$ \\
\hline \multirow[t]{2}{*}{$\geq 6$} & 7.95 & 3.00 & 1.58 & 1.57 \\
\hline & $(6.02-10.50)$ & $(2.31-3.88)$ & $(1.10-2.51)$ & $(1.23-1.99)$ \\
\hline
\end{tabular}

*: Presented as odds ratios with $95 \%$ confidence intervals in parentheses, adjusted for family history of atopy, number of siblings, parental education, city and school grade; ${ }^{+}$: excluding children with asthma and current wheeze.

rather than categorical variables. Moreover, no effect on airway hyperresponsiveness was seen. Only for total serum $\operatorname{IgE}$ was an inverse association with the number of fever episodes during the first year of life, but not with the number of antibiotic treatments in the first three years of life, found (table 3 ). In turn, a significant inverse association between both the frequency of fever episodes and antibiotic courses in the first years of life and baseline pulmonary function (FEV1, maximal expiratory flow when 25 and $75 \%$ of forced vital capacity (FVC) remain (MEF50 and MEF25 respectively) and maximal midexpiratory flow between 25 and $75 \%$ of FVC (MMEF2575)) was seen after adjusting for sex, height, weight, study area, passive smoke exposure and a family history of atopy.

When stratifying the analysis for a diagnosis of asthma, however, a strong inverse relationship between the number of fever episodes and antibiotic courses during the first years of life and the manifestation of atopy and bronchial hyperresponsiveness (BHR) was observed among asthmatic school-aged children (table 4). For example, the risk of being sensitized to at least one aeroallergen as assessed by skin prick test was reduced to a quarter $(\mathrm{OR}=0.25$; 95\% CI 0.11-0.54) when at least five episodes of fever had occurred during the first year of life. In contrast, among children with asthma, baseline pulmonary function parameters were no longer affected. Among the nonasthmatic children, however, an inverse relationship between the number of fever episodes during the first year of life and baseline lung function (e.g. MEF50: $\beta$-coefficient $-0.05, \mathrm{p}=0.003$ ) was found. When stratifying the analysis for current wheeze, similar though somewhat weaker effects on atopy and BHR were found (data not shown). For example, the risk of being sensitized to at

Table 3. - Number of fever episodes and antibiotic during the first years of life and risk of atopic sensitization, bronchial hyperresponsiveness (BHR) and reduction of baseline lung function

\begin{tabular}{|c|c|c|c|c|c|c|}
\hline & $\begin{array}{l}\text { Skin prick test* } \\
(\mathrm{n}=5067)\end{array}$ & $\begin{array}{c}\text { RAST (Sx1)*** } \\
(\mathrm{n}=4050)\end{array}$ & $\begin{array}{l}\text { Total serum } \operatorname{IgE} E^{\#} \\
(\mathrm{n}=2045)\end{array}$ & $\begin{array}{c}\text { BHR* }^{*} \\
(\mathrm{n}=1629)\end{array}$ & $\begin{array}{c}\mathrm{FEV1}^{\#} \\
(\mathrm{n}=1946)\end{array}$ & $\begin{array}{l}\text { MEF50 } \\
(\mathrm{n}=1946)\end{array}$ \\
\hline \multicolumn{7}{|c|}{ Number of fever episodes in 1st yr } \\
\hline Never & 1.00 & 1.00 & $-19.02(\mathrm{p}=0.03)$ & 1.00 & $-0.02(p=0.014)$ & $-0.056(\mathrm{p}=0.0002)$ \\
\hline $1-2$ & $\begin{array}{c}0.94 \\
(0.78-1.13)\end{array}$ & $\begin{array}{c}0.96 \\
(0.80-1.14)\end{array}$ & & $\begin{array}{c}0.95 \\
(0.68-1.32)\end{array}$ & & \\
\hline $3-4$ & $\begin{array}{c}0.86 \\
(0.68-1.08)\end{array}$ & $\begin{array}{c}0.89 \\
(0.72-1.11)\end{array}$ & & $\begin{array}{c}1.03 \\
(0.69-1.54)\end{array}$ & & \\
\hline$\geq 5$ & $\begin{array}{c}0.85 \\
(0.65-1.10)\end{array}$ & $\begin{array}{c}0.82 \\
(0.62-1.04)\end{array}$ & & $\begin{array}{c}0.88 \\
(0.55-1.41)\end{array}$ & & \\
\hline \multicolumn{7}{|c|}{ Number of antibiotic courses in 1 st $3 \mathrm{yrs}$} \\
\hline Never & 1.00 & 1.00 & $1.03(\mathrm{p}=0.91)$ & 1.00 & $-0.02(p=0.002)$ & $-0.051(\mathrm{p}=0.0006)$ \\
\hline $1-2$ & $\begin{array}{c}0.96 \\
(0.80-1.17)\end{array}$ & $\begin{array}{c}0.93 \\
(0.77-1.13)\end{array}$ & & $\begin{array}{c}1.34 \\
(0.94-1.90)\end{array}$ & & \\
\hline $3-5$ & $\begin{array}{c}0.93 \\
(0.75-1.14)\end{array}$ & $\begin{array}{c}0.84 \\
(0.68-1.03)\end{array}$ & & $\begin{array}{c}1.52 \\
(1.04-2.22)\end{array}$ & & \\
\hline$\geq 6$ & $\begin{array}{c}0.92 \\
(0.72-1.17)\end{array}$ & $\begin{array}{c}0.99 \\
(0.78-1.25)\end{array}$ & & $\begin{array}{c}1.11 \\
(0.71-1.76)\end{array}$ & & \\
\hline
\end{tabular}

*: Odds ratios with $95 \%$ confidence intervals in parentheses, adjusted for family history of atopy, number of siblings, parental education, study area and school grade; ${ }^{\#}: \beta$-coefficient ( $\mathrm{p}$-value), adjusted for sex, height, weight, study area, passive smoke exposure and family history of atopy; ${ }^{*}$ : positive radioallergosorbent test (RAST) defined as $\geq 0.7 \mathrm{kU} \cdot \mathrm{L}^{-1}$ of specific serum immunoglobulin (Ig)E. BHR: bronchial hyperresponsiveness; FEV1: forced expiratory volume in one second; MEF50: mean maximal expiratory flow. 
Table 4. - Number of fever episodes and antibiotic courses during the first years of life and risk of atopic sensitization, bronchial hyperresponsiveness (BHR) and reduction in baseline lung function in asthmatic children

\begin{tabular}{|c|c|c|c|c|c|c|}
\hline & $\begin{array}{l}\text { Skin prick test* } \\
(\mathrm{n}=416)\end{array}$ & $\begin{array}{l}\text { RAST (Sx1)*** } \\
(\mathrm{n}=360)\end{array}$ & $\begin{array}{l}\text { Total serum } \operatorname{Ig} \mathrm{E}^{\#} \\
(\mathrm{n}=166)\end{array}$ & $\begin{array}{c}\text { BHR } \\
(\mathrm{n}=150)\end{array}$ & $\begin{array}{l}\mathrm{FEV1}^{\#} \\
(\mathrm{n}=178)\end{array}$ & $\begin{array}{l}\text { MEF50 } \\
(\mathrm{n}=178)\end{array}$ \\
\hline \multicolumn{7}{|c|}{ Number of fever episodes in 1 st yr } \\
\hline Never & 1.00 & 1.00 & \multirow[t]{7}{*}{$-142.92(\mathrm{p}=0.0001)$} & 1.00 & \multirow[t]{7}{*}{$-0.01(\mathrm{p}=0.5)$} & \multirow[t]{7}{*}{$-0.009(\mathrm{p}=0.8)$} \\
\hline \multirow[t]{2}{*}{$1-2$} & 0.62 & 0.48 & & 1.03 & & \\
\hline & $(0.30-1.27)$ & $(0.22-1.07)$ & & $(0.38-2.79)$ & & \\
\hline \multirow[t]{2}{*}{$3-4$} & 0.42 & 0.29 & & 0.77 & & \\
\hline & $(0.19-0.91)$ & $(0.12-0.67)$ & & $(0.25-2.37)$ & & \\
\hline \multirow{2}{*}{$\geq 5$} & 0.25 & 0.18 & & 0.31 & & \\
\hline & $(0.11-0.54)$ & $(0.08-0.41)$ & & $(0.10-0.92)$ & & \\
\hline \multicolumn{7}{|c|}{ Number of antibiotic courses in 1 st $3 \mathrm{yrs}$} \\
\hline Never & 1.00 & 1.00 & $-82.93(\mathrm{p}=0.027)$ & 1.00 & $-0.02(\mathrm{p}=0.2)$ & $-0.04(\mathrm{p}=0.4)$ \\
\hline \multirow[t]{2}{*}{$1-2$} & 0.62 & 0.57 & & 1.79 & & \\
\hline & $(0.27-1.39)$ & $(0.23-1.43)$ & & $(0.61-5.23)$ & & \\
\hline \multirow[t]{2}{*}{$3-5$} & 0.37 & 0.25 & & 0.43 & & \\
\hline & $(0.17-0.81)$ & $(0.10-0.61)$ & & $(0.14-1.33)$ & & \\
\hline \multirow[t]{2}{*}{$\geq 6$} & 0.23 & 0.20 & & 0.43 & & \\
\hline & $(0.10-0.50)$ & $(0.08-0.48)$ & & $(0.15-1.17)$ & & \\
\hline
\end{tabular}

For definitions of symbols and abbreviations, see footnote to table 3 .

least one aeroallergen as assessed by skin prick test was reduced to a third $(\mathrm{OR}=0.31 ; 95 \% \mathrm{CI} 0.10-0.92)$ when at least five episodes of fever had occurred during the first year of life.

The remission of symptoms of asthma during the previous 12 months was inversely related to the frequency of early childhood infections in both age groups (table 5). In $45 \%$ of children with a diagnosis of asthma and at least six antibiotic courses during the first 3 yrs of life, no asthma symptoms had occurred in the previous 12 months, whereas in children not requiring an antibiotic treatment during the first 3 yrs of life only $26 \%$ of asthmatic children had no symptoms in the previous 12 months $(\mathrm{p}<0.001$ for trend).

When separately considering children with atopic and nonatopic asthma, and asthmatic children with and without BHR, the strongest association between the frequency of infections during early childhood and a diagnosis of asthma at school age was found for nonatopic asthma (table 6). The risk of being diagnosed as asthmatic increased strongly $(\mathrm{OR}=24.3 ; 95 \%$ CI $11.9-49.8)$ with increasing exposure to early childhood infections among nonatopic children. For atopic asthma a similar though much weaker trend was found $(\mathrm{OR}=4.4 ; 95 \%$ CI 2.7-7.0).

Table 5. - Remission of symptoms among asthmatic children by increasing number of fever episodes and antibiotic courses during the first years of life

\begin{tabular}{llll}
\hline \multicolumn{4}{c}{ Absence of asthma symptoms } \\
\cline { 2 - 4 } & $\%$ & Patients n & Total n \\
\hline Number of fever episodes & & \\
None & 29.4 & 35 & 119 \\
$1-2$ & 35.6 & 114 & 320 \\
$3-4$ & 39.8 & 68 & 171 \\
$\geq 5$ & 47.0 & 85 & 181 \\
Number of antibiotic courses & & \\
None & 26.4 & 24 & 91 \\
$1-2$ & 35.2 & 69 & 196 \\
$3-5$ & 40.0 & 98 & 245 \\
$\geq 6$ & 45.3 & 45 & 254 \\
\hline
\end{tabular}

${ }^{\#}$ : $p<0.001$, Mantel-Haentzel Chi-squared test for trend.

\section{Discussion}

The results of this analysis suggest that repeated infections early in life are strongly associated with the prevalence of asthma and current wheeze at school age, particularly among nonatopic children. Within asthmatic children, the number of fever episodes and antibiotic courses during early childhood were strongly inversely related to the prevalence of atopic sensitization as assessed by skin prick test, RAST and total serum $\operatorname{IgE}$, and to airway hyperresponsiveness to a hypertonic saline challenge. Furthermore, asthmatic children with recurrent early childhood infections were at a lower risk of being symptomatic at school age. These findings suggest that a subgroup of children with a triggering or inducing of asthmatic symptoms through repeated early childhood infections exists within the "asthma syndrome" which has a better prognosis and is less related to the atopic phenotype.

Several methodological limitations must be considered before attempting to interpret these findings. Firstly, there is no universally accepted definition of asthma. A doctor's diagnosis of asthma and of synonyms frequency used by German paediatricians and general practitioners was used to describe asthma. Such a definition may skew the observed characteristics of the group towards more severe cases, whereas the use of asthma-related symptoms such as wheeze may also include milder manifestations of the illness. Regardless of the applied definition similar relations between the exposure to infections early in life and asthma or current wheeze were found. The association with wheeze was, however, weaker than with asthma. This difference may be attributable to differences in the estimates; for asthma the life time prevalence was assessed, whereas the 12 month period prevalence was calculated for wheezing symptoms.

Because of the cross-sectional study design the frequency of fever episodes and antibiotic treatments during the first years of life was assessed retrospectively by parental questionnaires. Parents of symptomatic children may tend to remember and report previous illnesses more accurately than parents of asymptomatic children who may forget early health problems more readily. The stronger 
Table 6. - Risk* of asthma with and without atopy ${ }^{\$}$ and bronchial hyperresponsiveness $(\mathrm{BHR})$ respectively, with increasing number of fever episodes and antibiotic courses during the first years of life

\begin{tabular}{|c|c|c|c|c|}
\hline & $\begin{array}{l}\text { Atopic asthma } \\
\quad(\mathrm{n}=8215)\end{array}$ & $\begin{array}{l}\text { Nonatopic asthma } \\
\quad(\mathrm{n}=8187)\end{array}$ & $\begin{array}{l}\text { Asthma with BHR } \\
\qquad(\mathrm{n}=8083)\end{array}$ & $\begin{array}{l}\text { Asthma without BHR } \\
\qquad(\mathrm{n}=8109)\end{array}$ \\
\hline \multicolumn{5}{|c|}{ Number of fever episodes in 1 st year } \\
\hline Never & 1.00 & 1.00 & 1.00 & 1.00 \\
\hline $1-2$ & 1.03 & 2.18 & 1.01 & 0.98 \\
\hline & $(0.69-1.55)$ & $(1.14-4.16)$ & $(0.50-2.04)$ & $(0.48-1.98)$ \\
\hline $3-4$ & $\begin{array}{c}1.33 \\
(0.83-214)\end{array}$ & $\begin{array}{c}4.5 \\
32-888)\end{array}$ & $\begin{array}{c}1.38 \\
(01-3)\end{array}$ & $\begin{array}{c}1.82 \\
0.85-391)\end{array}$ \\
\hline$\geq 5$ & $\begin{array}{c}2.31 \\
(1.43-3.74)\end{array}$ & $\begin{array}{c}11.48 \\
(5.95-22.12)\end{array}$ & $\begin{array}{c}2.04 \\
(0.86-4.85)\end{array}$ & $\begin{array}{c}6.05 \\
(3.37-13.50)\end{array}$ \\
\hline \multicolumn{5}{|c|}{ Number of antibiotic courses in 1 st $3 \mathrm{yrs}$} \\
\hline Never & 1.00 & 1.00 & 1.00 & 1.00 \\
\hline $1-2$ & $\begin{array}{c}1.10 \\
(070-173)\end{array}$ & $\begin{array}{c}2.39 \\
(13-508)\end{array}$ & $\begin{array}{c}1.41 \\
(08-292)\end{array}$ & $\begin{array}{c}0.85 \\
(039-185)\end{array}$ \\
\hline $3-5$ & $\begin{array}{c}1.69 \\
(1.06-2.70)\end{array}$ & $\begin{array}{c}6.82 \\
(3.32-14.00)\end{array}$ & $\begin{array}{c}0.97 \\
(0.40-2.34)\end{array}$ & $\begin{array}{c}2.28 \\
(1.11-4.66)\end{array}$ \\
\hline$\geq 6$ & $\begin{array}{c}4.38 \\
(2.73-7.01)\end{array}$ & $\begin{array}{c}24.29 \\
(11.86-49.76)\end{array}$ & $\begin{array}{c}3.76 \\
(1.66-8.50)\end{array}$ & $\begin{array}{c}9.71 \\
(4.88-19.32)\end{array}$ \\
\hline
\end{tabular}

*: odds ratios with $95 \%$ confidence limits in parentheses adjusted for family history of atopy, number of siblings, parental education, study area and school grade; ${ }^{\$}$ : children with asthma and specific serum immunoglobulin $\geq 0.7 \mathrm{kU} \cdot \mathrm{L}^{-1}$.

association between the frequency of early childhood infections and asthma in the younger age group may support this argument. However, children with infection-associated wheeze had a higher degree of remission of symptoms than children with atopic asthma, suggesting that in the younger age group the relation between infections and asthma is in fact stronger than in older age when a significant proportion of subjects have lost their symptoms.

Such differential recall may have biased the results towards stronger effects. However, the reliability of responses assessing early childhood infectious episodes did not differ significantly between asthmatic and nonasthmatic children. Moreover, the dose-response relationship between exposure and outcome, the strength of the effect and the strong inverse relationship with atopy and BHR among the asthmatic children make it very unlikely that the association is entirely attributable to bias. Moreover, the stronger relationship between the frequency of early childhood infections and asthma in the younger age group may also be attributable to a higher degree of remission of symptoms among children with infection-associated wheeze than among atopic asthmatic children. In turn, by counting the number of episodes with fever $>38.5^{\circ} \mathrm{C}$ and the number of antibiotic courses, the overall burden of early childhood infections may have been underestimated, since viral and bacterial infections not inducing fever or requiring an antibiotic regimen such as diarrhoea, rhinitis or asymptomatic infections will not have been assessed.

The reasons for repeated episodes of fever and courses of antibiotic treatment during the first years of life cannot be determined with certainty in epidemiological studies. Even in the presence of practice records the viral or bacterial nature of an infection may not be assessed accurately because antibiotics are often prescribed without initiating bacterial cultures and awaiting their results. Thus, the number of antibiotic courses may also reflect the frequency of viral infections. In fact, both exposure measures were associated (kappa $=0.37, \mathrm{p}=0.001$ ), but were independently related to asthma and current wheeze when introducing both variables simultaneously into the multi- variate logistic regression models (data not shown). This independent effect may point towards differences in the underlying nature of the reported infections, differences in the severity of the symptoms, or alternatively to differences in the time frame of the questions, which assessed exposure during the first, and the first 3 yrs of life, respectively.

Children with increasing numbers of early childhood fever episodes and antibiotic courses were found to be at risk for the development of asthma and wheeze into school age as has been reported recently [16]. When attempting to interpret this finding, it must be remembered that an odds ratio reflects the strength but not the direction of an association. Thus, an increased risk of asthma and wheeze associated with increasing numbers of infectious episodes early in life may indicate a causal link whereby infections induce the development of new cases of asthma. However, the opposite is equally conceivable. An asthmatic subject's underlying increased susceptibility to acquire viral and/or bacterial infections early in life may also explain this relation. Finally, infants with a wheezing illness may be more likely to be treated with antibiotics in the absence of a definite diagnosis of asthma which cannot be established with certainty at this young age [17].

The role of viral infections, particularly RSV infections, for the inception of childhood asthma has been intensely debated [18]. In prospective studies, schoolchildren with a history of bronchiolitis during infancy were found to have impaired lung function at school age [1-3]. These wheezing lower respiratory tract illnesses (LRIs) due to RSV or other viruses were therefore thought to alter normal lung development and produce long-lasting sequelae that induce the development of asthma later in life. However, a host factor predisposing to both LRIs and subsequent abnormalities in lung function could also explain these associations. Recent studies [19-21] have in fact shown that diminished lung function assessed as a reduction in maximal expiratory flow at functional residual capacity ( $\left.V^{\prime} \max , \mathrm{FRC}\right)[21,22]$ and in the pulmonary function (Tme/ TE ratio) [20] is a predisposing factor for the development of a subsequent wheezing illness in infancy. Results 
of the Tucson Cohort [22] suggest that these infants start wheezing early in life but usually have no reports of wheezing as assessed at $\geq 3$ yrs of age [22]. This form of wheezing was associated with a good prognosis and showed no association with parental history of asthma, atopic symptoms or with the production of $\operatorname{IgE}$ in the child.

Interestingly, in the data presented herein several baseline pulmonary function parameters (FEV1, MEF50, MEF25 and MMEF25-75) were inversely related to repeated infectious episodes early in life. This association was, however, only seen in nonasthmatic children suggesting that the small airways may predict a certain susceptibility to repeated episodes of fever early in life which may or may not be associated with wheezing symptoms, but do not result in a doctor's diagnosis of asthma at school age. In fact, when separately analysing children who wheezed during the first years of life but stopped wheezing at around their third birthday (25.8\% of ever wheezing children), a significant reduction in MEF50 with increasing numbers of fever episodes was seen, in spite of a low number of subjects $(n=76 ; \beta$-coefficient $-0.19, p=0.01)$. However, no relationship between pulmonary function and the occurrence of early childhood infections was found in children wheezing after the age of 3 yrs. Thus, in contrast to the transient early wheezing phenotype described by MARTINEZ and coworkers [20, 22], the increased risk of current wheeze and asthma with repeated infectious episodes early in life observed in this cross-sectional survey may not be attributable to premorbid impaired lung function.

The wheezing phenotype described herein may be associated with an increased susceptibility to acquire viral and/or bacterial infections but does not relate to atopy or airway hyperresponsiveness. This subgroup may correspond to the "wheezy bronchitis" described in UK studies $[23,24]$, which was defined as recurrent wheezing episodes triggered by viral infections only, whereas asthma was considered as wheeze triggered by a wide array of factors such as allergen exposure, exercise, physical stimuli, etc. Several longitudinal studies [25-27] have in fact shown that the presence and severity of atopy and airway hyperresponsiveness increase the risk of persisting asthma and BHR throughout adolescence, which is in accordance with the present results. Thus, the remission of asthma seen over puberty may in part be attributable to a decrease in the frequency of wheezing episodes with infections rather than to a remission of symptoms among atopic asthmatic subjects.

The reasons for these different manifestations of wheezing illnesses within the complex syndrome of childhood "asthma" are unknown. Genetic heterogeneity with a polygenic/oligogenic mechanism whereby, many genes participate in the inheritance mechanism of "asthma", may potentially explain these findings. Mutations in genes which regulate mechanisms of increased susceptibility to viral infections such as enhanced intracellular adhesion molecule (ICAM)-1 expression [28], may or may not be linked to genes regulating the immune response towards environmental allergens. For the identification of candidate genes for "asthma", a careful phenotypic characterization of affected subjects will be essential.

In addition to genetic influences, environmental factors may also contribute to the phenotypic heterogeneity of the asthmatic condition. High exposure to viral and/or bac- terial infections early in life may in certain predisposed subjects downregulate T-helper 2 immune responses which have been shown to induce IgE antibody production [29]. Several epidemiological studies have furthermore demonstrated a protective effect of recurrent early childhood infections for the development of atopy [7, 8]. This mechanism may require a certain genetic predisposition as has recently been suggested [30]. Thereby, in genetically predisposed subjects, increasing numbers of infectious episodes may result in recurrent episodes of wheezy bronchitis with favourable prognosis and reduced risk of atopic sensitization and airway hyperresponsiveness. Indirect evidence to support this notion comes from epidemiological surveys which have shown a high prevalence of wheeze, bronchitis and pneumonia but not atopy and airway hyperresponsiveness in populations highly exposed to infectious diseases, whereas in less exposed populations atopy-related asthma with airway hyperresponsiveness was more prevalent $[5,6,31]$.

In summary, these findings suggest that up to school age, different wheezing phenotypes exist within the "asthma syndrome". This notion may be relevant for undertaking further genetic analyses, but may also reinforce previous reports suggesting that the prognosis of childhood "asthma" may depend not only upon the severity of symptoms but also on the presence and severity of atopic sensitization which has developed during childhood years.

\section{References}

1. Long CE, McBride JT, Hall CB. Sequelae of respiratory syncytial virus infections. A role for intervention studies. Am J Respir Crit Care Med 1995; 151: 1678-1681.

2. Sims D, Downham M, Gardner P, Webb J, Weightman D. Study of 8 year old children with a history of RSV bronchiolitis in infancy. BMJ 1978; 1: 11-14.

3. Pullan CR, Hey N. Wheezing, asthma and pulmonary dysfunction 10 years after infection with respiratory syncytial virus in infancy. BMJ 1982; 284: 1665-1669.

4. Sigurs N, Bjarnason R, Sigurbergsson F, Kjellman B, Bjorksten B. Asthma and immunoglobulin E antibodies after respiratory syncytial virus bronchiolitis: a prospective cohort study with matched controls. Pediatrics 1995; 95: 500-505.

5. Flynn MGL. Respiratory symptoms, bronchial responsiveness, and atopy in Fijian and Indian children. Am J Respir Crit Care Med 1994; 150: 415-420.

6. Flynn MGL. Respiratory symptoms of rural Fijian and Indian children in Fiji. Thorax 1994; 49: 1201-1204.

7. Matricardi PM, Rosmini F, Ferrigno L, et al. Cross sectional retrospective study of prevalence of atopy among Italian military students with antibodies against hepatitis A virus. BMJ 1997; 314: 999-1003.

8. Martinez FD, Stern DA, Wright AL, Taussig LM, Halonen M, GHM Associates. Association of non-wheezing lower respiratory tract illnesses in early life with persistently diminished serum IgE levels. Thorax 1995; 50: 1067-1072.

9. ISAAC Steering Committee. Phase II Modules of the International Study of Asthma and Allergies in Childhood (ISAAC). Münster, 1998.

10. Asher MI, Anderson JIR, Beasley R, et al. International Study of Asthma and Allergies in Childhood (ISAAC): rationale and methods. Eur Respir J 1995; 8: 483-491. 
11. The ISAAC Study Group. Worldwide variations in the prevalence of atopic diseases: the International Study of Asthma and Allergies in Childhood (ISAAC). Lancet 1998; 351: 1225-1232.

12. Gardner RM, Hankinson JL, Clausen JL, Crapo RO, Johnson RL, Epler GR. Standardization of spirometry: 1987 update. Official statement of the American Thoracic Society. Am Rev Respir Dis 1987; 136: 1285-1298.

13. Riedler J, Reade T, Dalton M, Holst D, Robertson C. Hypertonic saline challenge in an epidemiologic survey of asthma in children. Am J Respir Crit Care Med 1994; 150: 1632-1639.

14. Zapletal A, Paul F, Samanek M. The role of modern techniques of lung function testing for the diagnosis of airway obstruction in children and adolescents (in German). Z Erkrank Atm Org 1977; 149: 343-371.

15. Kabesch M, Schaal W, Nicolai T, von Mutius E. Lower prevalence of asthma and atopy in Turkish children living in Germany. Eur Respir J 1999; 13: 577-582.

16. Farooqi IS, Hopkin JM. Early childhood infection and atopic disorder. Thorax 1998; 53: 932.

17. Jones K, Gruffydd-Jones K. Management of acute asthma attacks associated with respiratory tract infection: a postal survey of general practitioners in the U.K. Respir Med 1996; 90: 419-425.

18. Price JF. Acute and long-term effects of viral bronchiolitis in infancy. Lung 1990; 168: Suppl. 168, 414-421.

19. Martinez FD, Morgan WJ, Wright AL, Holberg CJ, Taussig LM. Diminished lung function as a predisposing factor for wheezing respiratory illness in infants. $N$ Engl $J$ Med 1988; 319: 1112-1117.

20. Martinez FD, Morgan WJ, Wright AL, Holberg C, Taussig LM. Initial airway function is a risk factor for recurrent wheezing respiratory illnesses during the first three years of life. Group Health Medical Associates. Am Rev Respir Dis 1991; 143: 312-316.
21. Young S, O'Keeffe PT, Arnott J, Landau LI. Lung function, airway responsiveness, and respiratory symptoms before and after bronchiolitis. Arch Dis Child 1995; 72: 16-24.

22. Martinez FD, Wright AL, Taussig LM, Holberg CJ, Halonen M, Morgan WJ, GHMA Personnel. Asthma and wheezing in the first six years of life. N Engl J Med 1995; 332: 133-138.

23. Wilson NM. Wheezy bronchitis revisited. Arch Dis Child 1989; 64: 1194-1199.

24. Wilson NM. The significance of early wheezing. Clin Exp Allergy 1994; 24: 522-529.

25. Roorda RJ, Gerritsen J, Van Aalderen WM, et al. Risk factors for the persistence of respiratory symptoms in childhood asthma. Am Rev Respir Dis 1993; 148: 1490-1495.

26. Roorda RJ, Gerritsen J, van Alderen WMC, et al. Followup of asthma from childhood to adulthood: influence of potential childhood risk factors on the outcome of pulmonary function and bronchial responsiveness in adulthood. J Allergy Clin Immunol 1994; 93: 575-584.

27. Burrows B, Sears MR, Flannery EM, Herbison GP, Holdaway MD, Silva PA. Relation of the course of bronchial responsiveness from age 9 to age 15 to allergy. Am J Respir Crit Care Med 1995; 152: 1302-1308.

28. Rowlands DJ. Rhinoviruses and cells: molecular aspects. Am J Respir Crit Care Med 1995; 152: S31-S35.

29. Romagnani S. Human TH1 and TH2 subsets: regulation of differentiation and role in protection and immunopathology. Int Arch Allergy Immunol 1992; 98: 279-285.

30. von Mutius E. The influence of birth order on the expression of atopy in families: a gene-environment interaction? Clin Exp Allergy 1998; 28: 1454-1456.

31. von Mutius E, Martinez FD, Fritzsch C, Nicolai T, Roell G, Thiemann HH. Prevalence of asthma and atopy in two areas of West and East Germany. Am J Respir Crit Care Med 1994; 149: 358-364. 